\title{
Cytokine gene expression in the BB rat pancreas: natural course and impact of bacterial vaccines
}

\author{
H . Kolb ${ }^{1}$, U . Wörz-Pagenstert ${ }^{1}$, R . K leemann ${ }^{1}$, H . R othe ${ }^{1}$, P. R owsell ${ }^{2}$, F. W. Scott ${ }^{2}$ \\ ${ }^{1} \mathrm{D}$ iabetes R esearch Institute at the $\mathrm{H}$ einrich-H eine-U niversity of D üsseldorf, G ermany \\ ${ }^{2}$ Nutrition R esearch Division, H ealth Canada, Ottawa, Canada
}

Summary In diabetes prone B B rat pancreas the Th1/ Th2 cytokine balance and the expression of inducible nitric oxide synthase (iNOS) was determined by mR N A analysis before and after the onset of insulitis. Specific mRNA was amplified by reverse transcriptase polymerase chain reaction, quantitated with radiolabelled probes by phosphoimaging and calibrated with the amount of co-amplified $\beta$-actin mR NA . A t 50 days of age, prior to recognizeable insulitis, there was already significantly enhanced expression of both, Th1 and Th2 cytokines, and of iN OS mR NA, when compared to Wistar rat pancreas $(p<0.001)$. This supports the concept of an inconspicuous early phase of islet infiltration by single immunocytes, called single cell insulitis. A t 70 days of age mononuclear infiltration of islets had begun and was associated with upregulation of interferon $\gamma$ (IFN $\gamma$ ) and iNOS, but downregulation of interleukin-10 and transforming growth factor $\beta$ mRNA $(p<0.001)$. These findings correlate the onset of insulitis with a shift of the Th1/Th2 cytokine balance towards Th1 cell reactivity. Indeed there was a close correlation of the Th1/Th2 cytokine ratio but not of absolute IF $\gamma$ mR NA levels with the insulitis score.
Vaccination at day 50 with tetanus toxoid did not affect cytokine gene expression while diphtheria toxoid and even more strongly BCG administration induced a shift towards Th2 reactivity $(p<0.001)$ while iN OS mRNA was decreased $(p<0.01)$. O ral dosing with immunostimulatory components of E scherichia coli also changed the quality of inflammation. Oral lipopolysaccharide (LPS) from E. coli and O M-89, an endotoxin free extract containing immunostimulatory glycolipopeptides and heat shock protein (hsp) 65 , both downregulated IF $\gamma$ mR NA while only O M -89 in addition suppressed iNOS mRNA and enhanced Th2 cytokine gene expression $(p<0.001)$. We conclude that the onset of insulitis is associated with a shift towards Th1 cytokine and iNOS gene expression. D iphtheria toxoid and BCG vaccination stimulates Th2 reactivity but does not downregulate Th1. The latter can be achieved through oral administration of LPS or a glycopeptide fraction (O M -89) from E .coli. [D iabetologia (1996) 39: 1448-1454]

Keywords BB rat, insulitis, cytokines, inducible NO synthase, BCG, tetanus toxoid, lipopolysaccharide.
R eceived: 3 A pril 1996 and in final revised form: 6 September 1996

Corresponding author: Prof. D r. H.Kolb, Diabetes R esearch Institute, A uf'm Hennekamp 65, D-40225 D üsseldorf, Germany

A bbreviations: NOD, N on-obese diabetic; B B, B io-B reeding; $I L$, interleukin; IFN, interferon; iNOS, inducible nitric oxide synthase; RT-PCR, reverse transcriptase-polymerase chain rreaction; T G F $\beta$, transforming growth factor $\beta$; hsp, heat shock protein.
R ecent studies in the diabetes prone non-obese diabetic (NOD) mouse have led to the concept of two contrasting qualities of islet infiltration. A benign, non-destructive form is characterised by a dominance of Th2 cell reactivities as recognized by the local expression of Th2 cytokines interleukin (IL )-4 and IL 10, while there is little expression of the Th1 cytokine interferon $\gamma$ (IF $\gamma$ ). In contrast, beta-cell destructive insulitis is associated with enhanced expression of Th1 cytokines and of the inducible nitric oxide (NO) synthase (iNOS) [1-4]. Studies of the natural or 
cyclophosphamide accelerated course of insulitis showed that early peri-insular infiltration of islets is dominated by Th2 cells $[4,5]$ while the transition to intra-insular insulitis is associated with a rise in Th1 reactivity $[4,6,7]$, most probably initiated by the enhanced production of the Th 1 inducing cytokine IL - 12 in macrophages [8]. This shift from benign to destructive insulitis was shown to be suppressed when mice received vaccinations early in life with BCG or complete Freund's adjuvant [9-12], treatments that inhibited Th1 cytokine expression in inflamed islets $[1,2]$. Finally, islet-reactive clones of the Th1 but not of Th2 type were shown to adoptively transfer diabetes [13].

The natural course of insulitis in Bio-B reeding $(B B)$ rats differs strongly from NOD mice in that there is no pronounced and persisting peri-insular infiltration prior to the eventual progression to intra-insulitis. R ather, small foci of peri-ductular or peri-insular infiltrates progress to a mild and transient periinsulitis. M assive infiltration by mononuclear cells is only seen during intra-insulitis [14-16]. E arly infiltration stages are dominated by members of the macrophage/dendritic cell family, followed by $\mathrm{T}$ - and subsequently by B-lymphocytes [14-21].

We therefore compared the kinetics of Th1 and Th2 cytokine gene expression before and soon after the onset of insulitis in B B rats. Since the expression of the iNOS had been found to be linked closely to destructive insulitis in NOD mice, we included an analysis of iN OS MR NA.

Similarly, as reported in NOD mice, early treatment with bacterial vaccines has been reported to $a b-$ rogate or attenuate the disease process in BB rats [22-24]. The possible impact of such vaccinations on $\mathrm{Th} 1 / \mathrm{Th} 2$ cytokine balance and iN OS gene expression was measured as a further endpoint.

\section{Materials and methods}

Experimental animals. Diabetes prone B B rats were kindly provided by Dr. P.Thibert, A nimal Resources Division of Health Canada, Ottawa, Canada, where the stock animals were maintained under specific pathogen-free conditions. E xperimental animals were kept in 0 ttawa and in a parallel study at the animal facilities of the Diabetes Research Institute, D üsseldorf, Germany, under clean conventional conditions. R outine serological analyses confirmed bacterial and viral specific pathogen-free status. The initial experimental series in $\mathrm{Ot}$ tawa and repeat experiments in D üsseldorf were without apparent differences in results obtained. Wistar rats were from the Central A nimal Laboratory of the U niversity of $D$ üsseldorf. A nimals received a standard, open formula NIH-07 diet (Ziegler Brothers, Gardner, PA, USA ) and tap water ad libitum. A nimals were kept according to the respective national guidelines and experiments were approved by the local authorities.

Treatment of animals. $R$ ats were randomized into sex and litter matched control and experimental groups. Tetanus toxoid ( 8 units; B ehringwerke, M arburg, G ermany), diphtheria toxoid
(15 units, Behringwerke) or BCG $\left(1.3 \times 10^{7}\right.$ cells; Connaught, Toronto, Canada) were injected into the rear foot pad at 50 days of age. Lipopolysaccharide ( $1 \mathrm{mg}$, from E scherichia coli 0127 : B 8; Sigma, Geisenhofen, Germany) or OM-89 ( $40 \mathrm{mg} / \mathrm{kg}$ of $\mathrm{E}$. coli fraction; kindly provided by $\mathrm{D} \mathrm{r}$. J.-C. Farine, L aboratoires O M , G eneva, Switzerland) were administered orally in $1 \mathrm{ml}$ of phosphate buffered saline three times per week starting at 50 days of age. Control rats received vehicle only. The three vaccines and $\mathrm{OM}-89$ contained less than 12 parts per million endotoxin. D uring the experiment, animals were monitored twice weekly for body weight and glucosuria using test sticks. A t 70 days of age animals were killed. Blood glucose was determined by the hexokinase method. The pancreas was removed, split in half longitudinally and immediately snap frozen in pre-chilled isopentane and kept at $-70^{\circ} \mathrm{C}$. The two halves were analysed for islet infiltration and $\mathrm{mR}$ N A expression.

Histological analysis. Cryostat sections were prepared from three different regions of the pancreas, at least $100 \mu \mathrm{m}$ apart. For each animal, 10 islets of $100 \mu \mathrm{m}$ or more in diameter were analysed. Sections on coded slides were stained with haematoxylin and eosin and were evaluated for mononuclear infiltration after using the following semiquantitative rating system: score 0 , no detectable infiltrate; score 1 , small mostly focal infiltrate ( $\leq 5$ mononuclear cells) in the islet periphery; score 2 , infiltration by more than 5 mononuclear cells but less than $20 \%$ of the islet area infiltrated; score 3, more than $20 \%$ of the islet area infiltrated with pronounced intra-insulitis and loss of a clear frontier between endocrine and exocrine tissue. A Il sections were analysed by the same individual.

mRNA analysis. Total RNA was isolated by acid guanidinethiocyanate-phenol-chloroform extraction. A nalysis of specific mR NA was performed by reverse transcriptase polymerase chain reaction (RT-PCR) followed by quantitation of PCR products obtained. Specific primers for iNOS $[25,26]$, for IFN $\gamma$, transforming growth factor $\beta$ (TG F $\beta$ ) (Clontech L aboratories, Palo A Ito, Calif., U SA ), I L-10 [27] and $\beta$-actin (3' primer TCA TAG ATG GGC ACA GTG TG, 5' primer CTA A GG CCA ACC GTG AAA A G) were used in both steps of RT-PCR. O f total RNA $6 \mu \mathrm{g}$ was used for CDNA preparation. PCR was performed with hot start at $78^{\circ} \mathrm{C}$, followed by $5 \mathrm{~min}$ of denaturation at $95^{\circ} \mathrm{C}, 1 \mathrm{~min}$ of annealing at $60^{\circ} \mathrm{C}($ IF N $\gamma)$, $57^{\circ} \mathrm{C}(\mathrm{IL}-10), 55^{\circ} \mathrm{C}$ (iN OS), $62^{\circ} \mathrm{C}$ (TGF $\beta$ ) or $61^{\circ} \mathrm{C}$ ( $\beta$-actin) and 2 min of elongation phase at $72^{\circ} \mathrm{C}$. In the following cycles denaturation and elongation was for $1 \mathrm{~min}$. The final cycle had $7 \mathrm{~min}$ of elongation. Different $\mathrm{mRNA} s$ were amplified in different tubes. A fter a total of 35 cycles, the products were separated by electrophoresis on a $2 \%$ agarose gel. Q uantitation of PCR products was done as described previously [3] by hybridization to a specific ${ }^{32} \mathrm{P}$ labelled probe and determining ${ }^{32} \mathrm{P}$ stimulated luminescence by phosphoimaging. Counts obtained for iNOS and cytokine mR NA were calibrated to the amount of $\beta$-actin mR NA which was assigned a value of one. Two types of control experiments were performed with representative samples. For one, samples were run for only 20, 25 or 30 cycles to check for a linear increase of PCR products. Secondly, samples were run also $1: 3$ diluted to test for reproducibility of differences between mR NA types.

\section{Statistical analysis}

D ifferences between mean values were evaluated by two-sided Student's t-test, with a level of significance set as $p$ less than 0.05 . R egression analyses were done using Statview 4.01 software package. 
Results

Cytokine gene expression before and after onset of insulitis. A t 50 days of age about half of the B B rat pancreata analysed had minimal signs of islet infiltration with few mononuclear cells in the periphery of some islets or adjacent ducts. By 70 days of age insulitis had developed in 8 of 15 rats with peripheral or intra-insular infiltration, while the remainder still displayed minimal or no peri-insulitis (Fig.1). Hence, these two time points described the pancreas prior to and soon after the onset of classic, light microscopydefined mononuclear islet infiltration. These kinetics correlated well with the diabetes incidence observed; i. e. at 70 days of age $18 \%$ of B B rats had progressed to overt diabetes.

In pancreas R NA the message for IFN $\gamma$ and IL -10 was determined in order to recognize Th1-like as opposed to Th2-like immune cell activities. There was minimal or no cytokine mRNA detectable in Wistar rat pancreas (Fig. 2A). Surprisingly, mR NA of IF $\mathrm{N} \gamma$ and I L-10 was found in significantly elevated levels in the pancreas of 50 day old B B compared to Wistar rats $(p<0.001)$ despite the near lack of recognizable insulitis. Concomitantly with the progression of mononuclear infiltration of islets by 70 days of age a significant increase of IF $\mathrm{N} \gamma \mathrm{mRNA}$ levels was observed $(p<0.001)$ while a decrease of $I L-10$ mR N A was seen $(p<0.001)$ (Fig. $2 B)$.

In a parallel analysis we determined the expression of two genes reflecting the pro- or anti-inflammatory state of immune and also non-immune tissue cells. A s shown in Figure $2 \mathrm{~B}$, iNOS $\mathrm{mRNA}$ and TGF $\beta$ R N A levels were already elevated in the pancreas of 50 day old BB compared to Wistar rats $(p<0.001)$. With the onset of insulitis by 70 days of age there was a further increase in iNOS gene expression $(p<0.01)$ while TGF $\beta$ mRNA was downregulated $(p<0.01)$.

A $n$ analysis of possible correlations between individual Th1 cytokine $\mathrm{mR} N \mathrm{~A}$ levels and insulitis scores was performed (Fig. 3). Surprisingly, IF $\gamma$ mRNA levels correlated poorly with the insulitis score $(r=0.40, p>0.1)$. H owever, the ratio of IF N $\gamma$ vs IL $10 \mathrm{mR} N \mathrm{~A}$ closely reflected the state of islet inflammation $(r=0.78, p<0.001)$. M oreover, the four animals found to be hyperglycaemic had significantly higher ratios of IF $\gamma / / \mathrm{L}-10$ than the remainder of the rats $(p<0.05)$. Interestingly, only these four acutely diabetic animals showed background levels of both Th2 cytokine mR N A s, IL -10 and TG F $\beta$.

I mpact of bacterial vaccines on cytokine and iN OS expression. Three different vaccines were injected into the footpad and analyses of the possible effect on insulitis quality and quantity were performed as described above. Vaccination with tetanus toxoid did not affect Th1/Th2 cytokine gene expression in B B

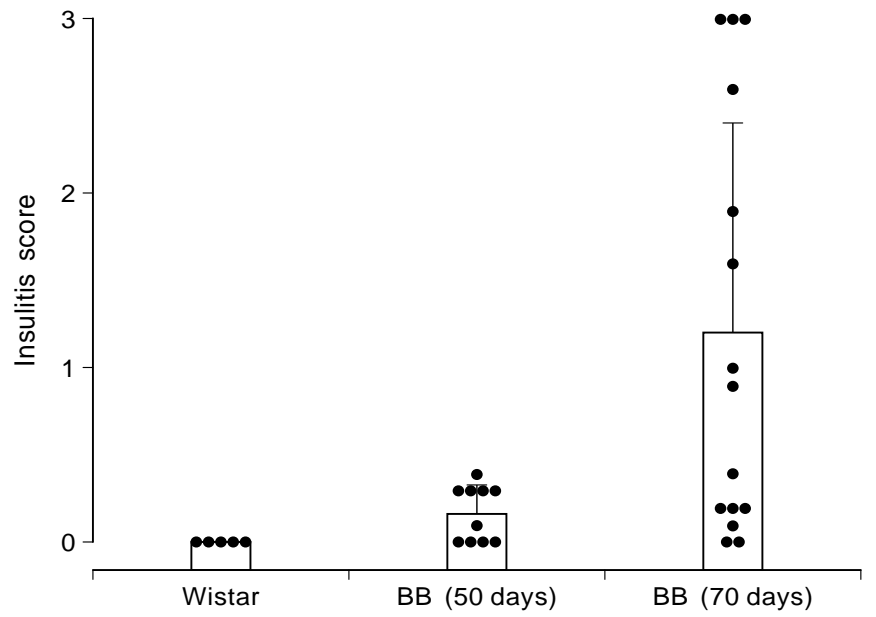

Fig. 1. O nset of insulitis in $B B$ rats. $E$ ach point represents one animal. The average score of 10 islets is shown for each animal. $B$ ars indicate means plus SD
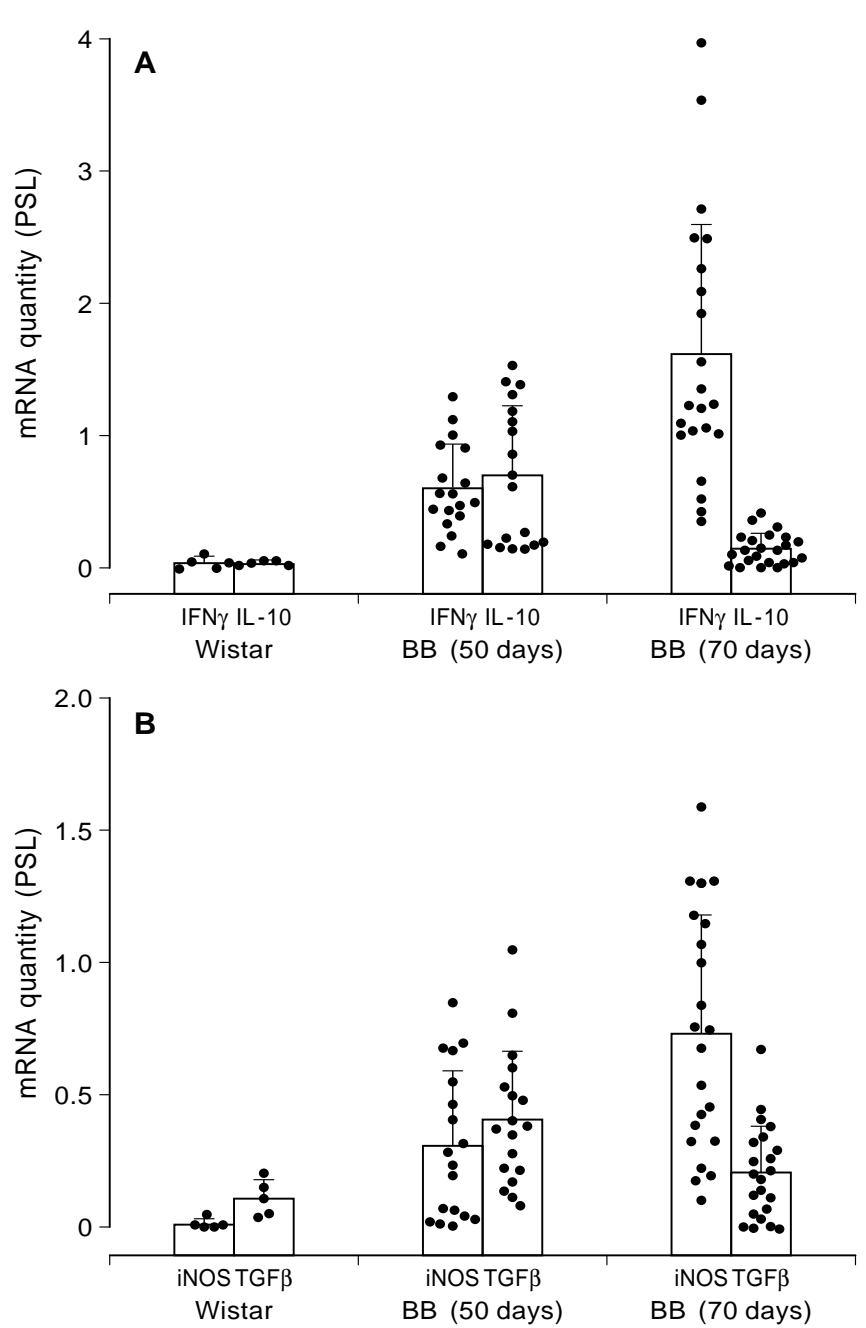

Fig. 2. A,B Cytokine and iNOS gene expression in $B B$ rat pancreas. E ach point represents one animal. $\mathrm{mR} N A$ levels for IFN $\gamma$, IL -10 (A) and iNOS, TGF $\beta$ (B) were determined by RT-PCR followed by quantitation of radiolabel by phosphor stimulated luminesence (PSL). Shown are mR NA levels calibrated to the amount of $\beta$-actin mR NA (set as 1 ). Bars indicate means plus SD 

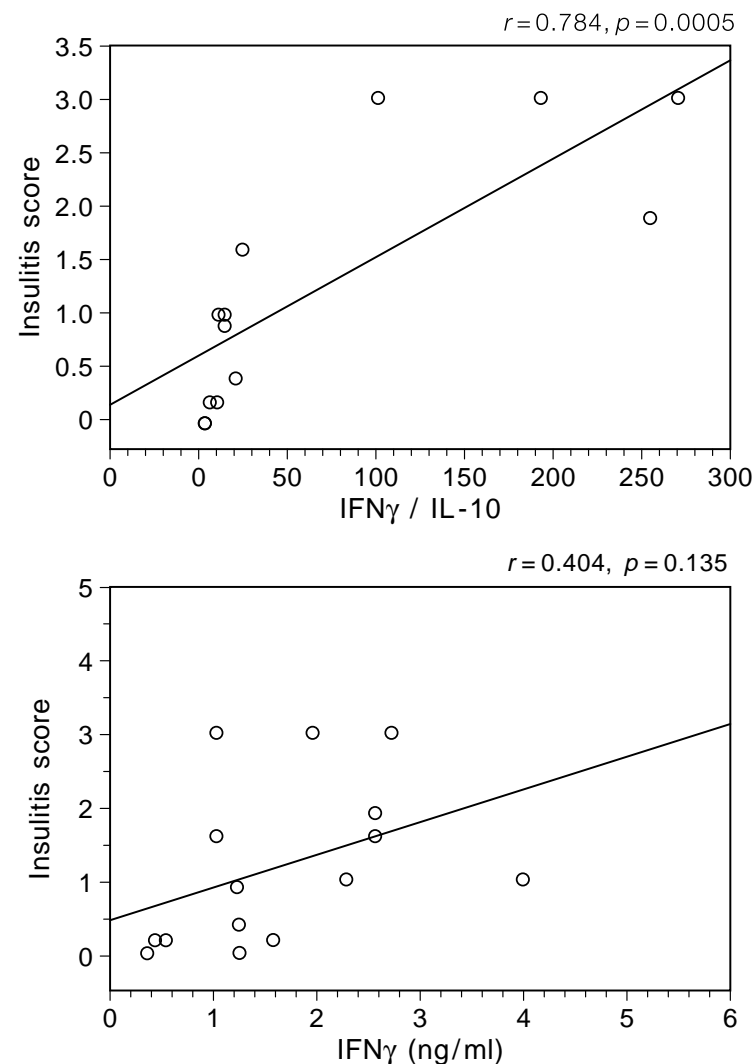

Fig. 3. R egression analysis of cytokine gene expression vs insulitis score. Each symbol represents an individual BB rat at 70 days of age

rat pancreas (Fig. 4A) nor did it alter the levels of iNOS and TGF $\beta$ mR NA (Fig.4B). The injection of diphtheria toxoid did not alter IFN $\gamma$ mRNA levels but significantly upregulated those of $\mathrm{IL}-10$ $(p<0.001)$ resulting in a decrease of the IF N $\gamma / I L-10$ ratio (Fig.4A). In parallel iNOS gene expression was downregulated $(p<0.05)$ and levels of counterregulatory TG F $\beta$ increased $(p<0.001$ ) (Fig. 4B).

The strongest effects on insulitis quality were observed after BCG vaccination, with a similar gene expression pattern as seen after diphtheria toxoid. There was no change of IF $\mathrm{N} \gamma \mathrm{mR} N \mathrm{~A}$ but a major upregulation of $\mathrm{IL}-10 \mathrm{mRNA}(\mathrm{p}<0.001)$ (Fig.4A), downregulation of iNOS mRNA $(p<0.01)$ and TGF $\beta$ gene expression was increased (Fig.4B, $p<0.001)$. In total, tetanus toxoid vaccination had no effect on pancreatic cytokine patterns while both diphtheria toxoid and BCG administration enhanced the gene expression of Th2 anti-inflammatory cytokines (IL-10, TG F $\beta$ ) and downregulated iNOS.

In parallel, a semi-quantitative analysis of insulitis was performed. A s shown in Figure $5 \mathrm{~A}$ there were no significant differences between the experimental and control groups for mean insulitis scores, indicating no effect on the degree of islet inflammation. A Iso, no effect of vaccination on body growth was detected.
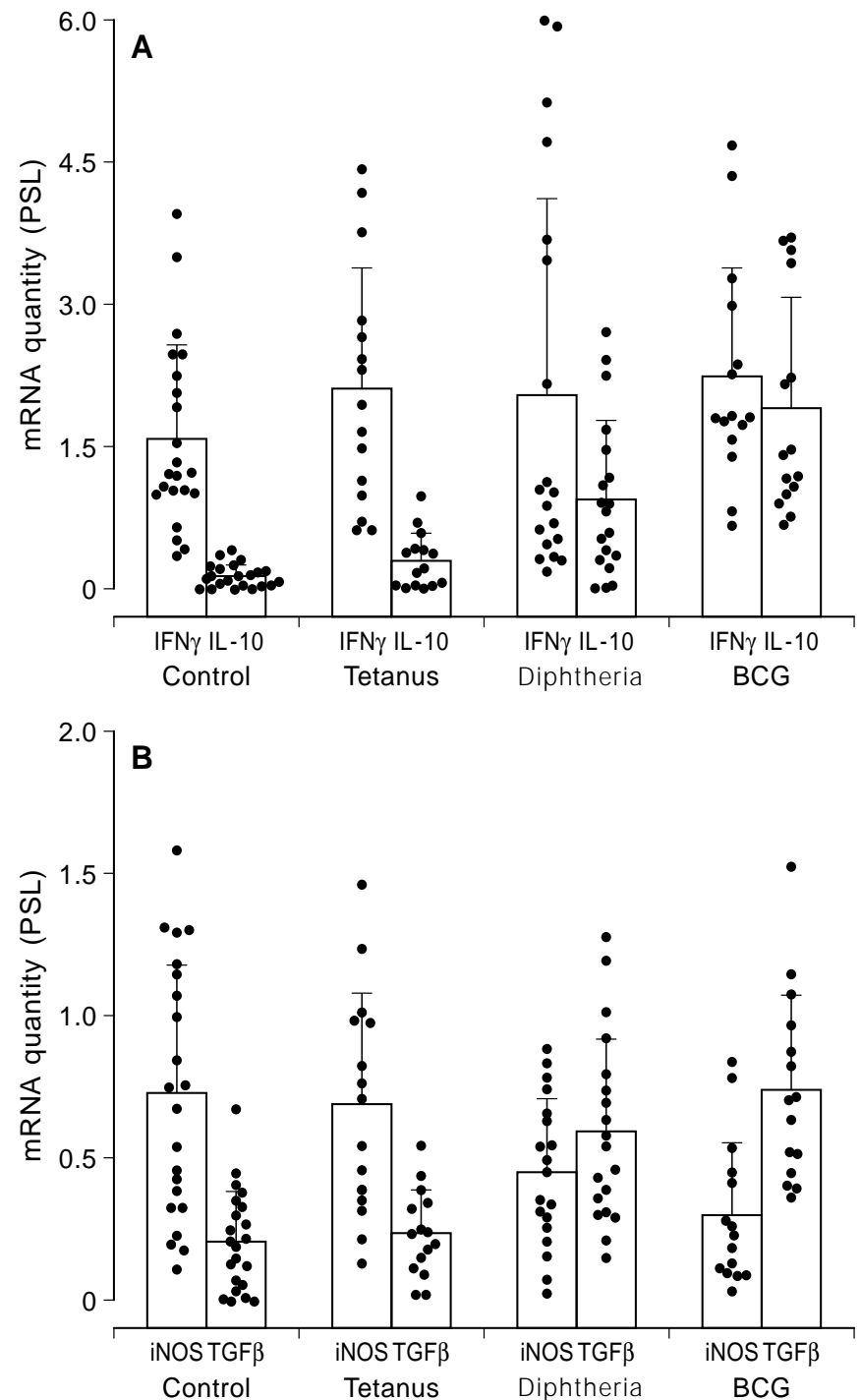

Fig. 4. A , B Impact of bacterial vaccines on cytokine and iNOS gene expression. $E$ ach point represents one animal. Shown are mR NA levels for IFN $\gamma$, IL -10 (A) and iNOS, TGF $\beta$ (B) calibrated to the amount of $\beta$-actin mRNA (set as 1 ) as determined by RT-PCR . B ars indicate means plus SD

Impact of orally administered E. coli fractions on cytokine and iNOS gene expression. Lipopolysaccharide or the endotoxin free glycoprotein preparation OM-89 from E.coli were given three times per week. Oral administration of the two immunostimulatory compounds had significant effects on cytokine and iNOS gene expression patterns. A s shown in Figure $6 \mathrm{~A}$ IFN $\gamma$ mRNA was significantly downregulated by both compounds $(p<0.001)$. OM-89 also had a stronger impact on the two other parameters, suppressing iNOS mRNA $(p<0.001)$ and strongly inducing TGF $\beta$ gene expression $(p<0.05)$ (Fig. 6B). A s seen before for the injected bacterial vaccines there was no suppression of islet infiltration in $B B$ rats receiving oral immunostimulation (Fig.5B). 


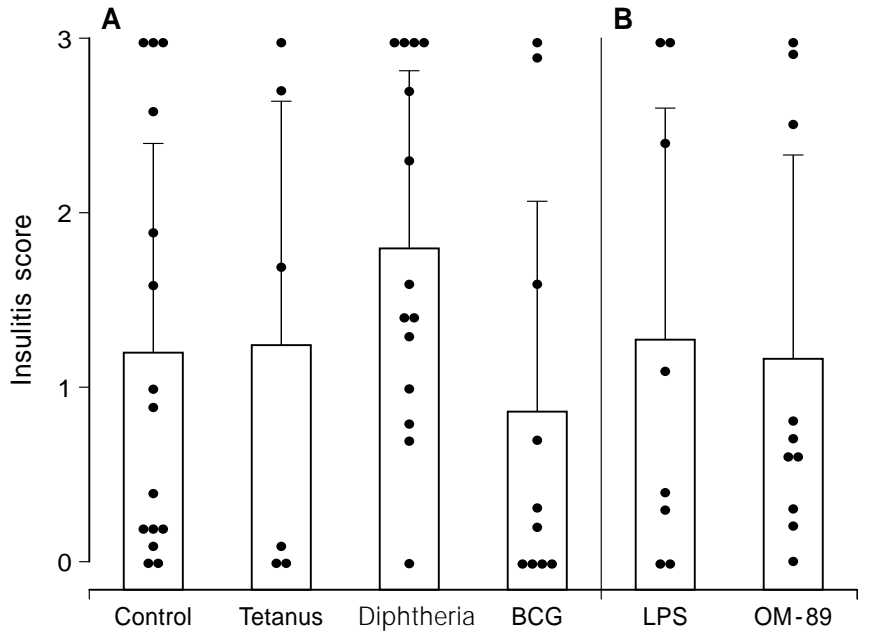

Fig. 5. A,B I mpact of bacterial vaccines and E. coli fractions on the onset of insulitis. $E$ ach point represents one animal of groups injected with saline or bacterial vaccines $(\mathbf{A})$ or orally treated with $\mathrm{E}$. coli fractions (B). The average score of 10 islets is shown per animal. $B$ ars indicate means plus SD
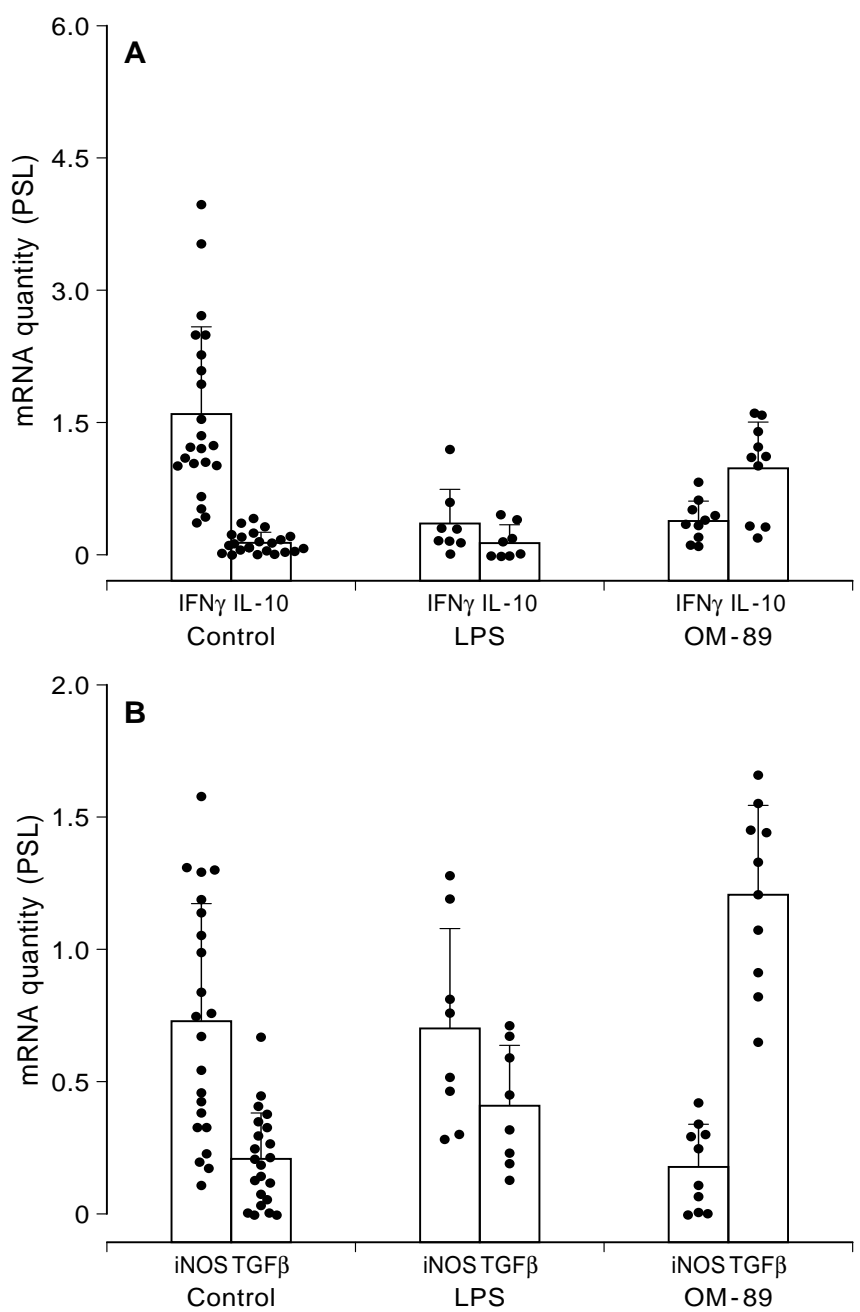

Fig. 6. A, B I mpact of orally administered $E$. coli fractions on cytokine gene expression. Shown are mR NA levels for IFN $\gamma$, IL -10 (A) and iNOS, TGF $\beta$ (B) calibrated to the amount of $\beta$-actin mR NA (set as 1 ) as determined by RT-PCR. Bars indicate means plus SD

\section{Discussion}

This study focused on the expression of key Th1 and Th2 cytokines and of iN OS mR NA in the BB rat pancreas before and after the onset of insulitis. I L - 10 was given preference over IL -4 in our analysis since in NOD mice IL - 10 but not IL -4 mR NA was found to correlate with Th2-type benign insulitis [4]. Some experiments were performed in parallel with RNA from freshly isolated islets. However, the latter approach yielded in our hands highly variable results while the analysis of total pancreatic RNA provided data correlating well with islet histology and disease state of the animal. A $n$ earlier study in NOD mice had also shown close correlation of mR NA detected in total pancreas with the immunohistochemically determined presence of cytokines or iN OS in islet sections [3]. Therefore, although cytokine and iNOS mR NA from whole pancreas also included message from non-endocrine tissue, the mR N A profile was in close accord with the histological determined state of islet inflammation. Several points render the use of RNA from isolated islets difficult. For one, the number of islets obtained from inflamed NOD mouse or B B rat pancreas is $25-50 \%$ lower than from tissue prior to insulitis onset. This suggests loss of damaged islets and enrichment for non-infiltrated or poorly infiltrated islets. Secondly, the isolation procedure includes several centrifugation steps which will favour the loss of peri-insular and in particular peri-ductular infiltrates. Finally, mR N A levels can be rapidly up- or downregulated, and such changes may occur during the in situ digestion period with collagenase at $37^{\circ} \mathrm{C}$.

The time points of the study were chosen to have one sample with minimal or no insulitis (at 50 days of age 4 pancreases appeared normal, in 6 cases there was minimal peri-insular infiltration (grade 1 ) in one or a few islets. The next time point chosen was at 70 days of age. By this time 8 of 15 rats had progressed to grade 2 or 3 insulitis in some or all of the islets, with 4 animals being acutely diabetic. R N A samples were not pooled before analysis but determined individually so that correlations between cytokines, iNOS and insulitis grade could be tested.

The data obtained reveal several characteristic features of the disease process. A t 50 days of age, the elevated cytokine and iN OS mR NA levels demonstrate the presence of an inflammatory process in the absence of classic, light microscopy-defined insulitis. These data are in accord with previous reports of single cell insulitis, an inconspicuous form of islet infiltration, recognizable only with the aid of an electron microscope $[28,29]$, and preceding "classical" insulitis. H owever, constitutively elevated cytokine and iNOS mR NA levels cannot be ruled out. A further argument in support of early inflammatory changes in the observation of IFN $\alpha$ expression in beta cells of young $B B$ rats which also indicates some inflammatory 
changes prior to insulitis [30]. In addition, a decrease in beta-cell volume has been noted prior to the onset of classical insulitis [31]. Focal infiltrates in the exocrine pancreas have been seen in the $B B$ rat and in man $[14,29,32,33]$ and they may contribute. It is of interest that this early stage is characterized by the expression of proinflammatory (IFN $\gamma$, iNOS) as well as counter-regulatory mediators (IL-10, TGF $\beta$ ). With the progression towards significant peri- and intra-insular infiltration, this balance shifts towards proinflammatory gene expression, while Th2 cytokine mRNA is decreased. To our knowledge, this is the first demonstration of a close individual correlation between the degree of insulitis and the Th1/Th2 balance. A $n$ earlier study demonstrated the expression of IL -1 , IF N $\gamma$, TNF $\alpha$ and IL - 6 mR N A in pancreata of acutely diabetic $B$ B rats by in situ hybridization [34]. There was an excess of tumour necrosis factor (TNF) $\alpha$ positive over I L- 6 positive cells during intrainsulitis, which is compatible with a dominance of Th1 reactivity [35]. A very recent study [35] demonstrated age-dependent increases of $\mathrm{mR} N \mathrm{~A}$ levels of IFN $\gamma$ and IL-12 p40 in islets of diabetes-prone BB rats, whereas IL-10 mR NA levels in islets did not change, except for a transient increase at 7 weeks of age in diabetes-prone B B rats. A Ithough the latter went uncommented by Zipris et al. [36], it supports our conclusion of an early contribution of Th2 reactivity followed by a dominance of Thl as insulitis progresses.

A nalysis of mR NA levels of single pancreata underscored the role of the Th1/Th2 balance. There was a close correlation between the individual insulitis score and the Th1/Th2 balance found. Surprisingly, the absolute level of IF $\gamma$ mR NA showed only poor correlation with insulitis scores; i.e. animals with high IF $\mathrm{N} \gamma \mathrm{mR} N \mathrm{~A}$ levels only had an advanced insulitis score if the level of IL-10 mR N A was low. We conclude that the immune status of an inflammatory infiltrate can only be assessed by determining the ratio of counter-regulatory cytokines or mediators. A recent study of peripheral mononuclear cells in man has also found the ratio of Th1 compared to Th2 cytokines to be the best reflection of the immunomodulatory status [37]. In addition, the ratio of IF N $\gamma /$ I L -10 was recognized as distinguishing patients with type I (insulin-dependent) diabetes from healthy individuals or patients with atopic dermatitis [38, 39].

The second part of our study dealt with the impact of treatment with bacterial vaccination on the cytokine balance in pancreatic lesions. Several laboratories have reported that the administration of highly immunogenic bacterial preparations or adjuvants suppressed diabetes development in BB rats or NOD mice but did not necessarily inhibit islet infiltration [9-12, 22-24]. In the NOD mice, these treatments were found to freeze the Th2 state of peripheral islet infiltration and inhibit the progression towards destructive Th1 insulitis [1, 4, 12]. The data presented here show that strongly immunogenic vaccines significantly inhibit the shift towards Th1 reactivity although the development of insulitis was not suppressed. Hence, despite major differences in the extent and kinetics of islet infiltration $B B$ rats and NOD mice respond quite similarly to bacterial immunostimulants.

O ur study included five different bacterial preparations, and the comparison of results obtained offers some further insight into the mechanisms involved. Tetanus toxoid was the only compound lacking general immunostimulatory properties and also did not affect mRNA levels or ratios. Hence, it is not the immune response to a foreign (bacterial) protein which accounts for the immunoregulatory effect of the bacterial preparations. Secondly, a single subcutaneous injection of BCG or diphtheria toxoid did not "normalize" the Th1/Th2 balance by inhibiting the production of IFN $\gamma$ mRNA but upregulated the counter-regulatory IL-10 and TG F $\beta$. A s a consequence, there was a downregulation of inflammatory activity, as apparent from the significantly decreased iNOS mRNA levels, despite the persistence of elevated IFN $\gamma$ mRNA levels. Inhibition of IFN $\gamma$ gene expression was only reached after repeated oral administration of lipopolysaccharide or OM-89. The E. coli extract OM-89 contains mainly acidic glycolipoproteins of $10-300 \mathrm{kD}$ a molecular weight and mostly unknown nature, heat shock protein (hsp) 65 and minimal amounts of lipopolysaccharide ( $<12$ ppm) $[24,40,41]$. H sp 65 is also an immunodominant antigen of $B C G$. Whether the hsp 65 content of BCG and OM-89 is similar, has not been reported. OM-89 administration turned out to be more strongly anti-inflammatory than lipopolysaccharide in that there was not only downregulation of IFN $\gamma$ mRNA but also upregulation of both Th2 cytokine mR NA s. With respect to an eventual application in man it is important to learn that orally administered bacterial preparations may have an impact on the quality of islet inflammation. Interestingly, O M -89 was shown to ameliorate clinical measures of rheumatoid arthritis in placebo-controlled trials [40].

We conclude that immunostimulatory bacterial preparations exert strong effects on the $\mathrm{Th} 1 / \mathrm{Th} 2$ ratio of insulitis. Whether changes in the Th1/Th2 ratio will delay or prevent diabetes development depend on the extent and duration of such effects. D osing and timing of bacterial vaccinations will be important.

Further studies are warranted to elucidate the mechanism of action and therapeutic effects of bacterial immunostimulants on autoimmune disease. The ratio of Th1/Th2 cytokine gene expression, as described here, may become a useful tool for monitoring the immunoregulatory effect of these compounds. 
A cknowledgements. We thank M rs. G. Bosse for typing the manuscript, Mrs.M.Rinker for technical assistance and Dr. B.K allmann for help with statistical analyses. We acknowledge the assistance of M rs. J. Souligny in carrying out the animal studies in $\mathrm{O}$ ttawa. This work was supported by the B undesminister für $\mathrm{G}$ esundheit, the $\mathrm{B}$ undesminister für Bildung, Wissenschaft und Forschung und Technologie and by the $M$ inister für Wissenschaft und Forschung des L andes N ordrhein-Westfalen.

\section{References}

1. Shehadeh N N, La R osa F, L afferty KJ (1993) A Itered cytokine activity in adjuvant inhibition of autoimmune diabetes. J A utoimmunity 6: 291-300

2. Rabinovitch A (1994) Immunoregulatory and cytokine imbalances in the pathogenesis of ID D M. D iabetes 43: 613-621

3. Rothe H, Faust A, Schade U et al. (1994) Cyclophosphamide treatment of female non-obese diabetic mice causes enhanced expression of inducible nitric oxide synthase and interferon-gamma, but not of interleukin-4. D iabetologia 37: 1154-1158

4. R abinovitch A, Sorensen O, Suarez-Pinzon W L, Power R F, R ajotte RV, B leackley R C (1994) A nalysis of cytokine mR NA expression in syngenic islet grafts of NOD mice: interleukin-2 and interferon-gamma mRNA expression correlate with graft rejection and interleukin-10 with graft survival. D iabetologia 37: 833-845

5. A nderson J T, Cornelius J G, Jarpe A J, Winter WE, Peck A B (1993) Insulin-dependent diabetes in the NOD mouse model II $\beta$ cell destruction in the autoimmune diabetes is a Th2 and not a Th1 mediated event. A utoimmunity 15: 113-122

6. Campbell IL, K ay TWH , O xbrow L, H arrison L C (1991) E ssential role for interferon-gamma and interleukin- 6 in autoimmune insulin-dependent diabetes in NOD/Wehi mice. J Clin Invest 87: 739742

7. Trembleau S, Penna G, B osi E, M ortara A , G ately M K, A dorini L (1995) Interleukin-12 administration induces T helper cells and accelerates autoimmune diabetes in NOD mice. J Exp Med 181: 817-821

8. R othe H, B urkart V, Faust A, Kolb H (1996) Interleukin-12 gene expression is associated with rapid development of diabetes mellitus in non-obese diabetic mice. D iabetologia 39: 119-122

9. H arada M , K ishimoto Y, M akino S (1990) Prevention of overt diabetes and insulitis in NOD mice by a single BCG vaccination. Diabetes R es Clin Prac 8: 85-89

10. Sadelain M W J, Q in HY, Lauzon J, Singh B (1990) Prevention of type I diabetes in NOD mice by adjuvent immunotherapy. D iabetes 39: 583-589

11. M cl nerney M F, Pek SB, Thomas DW (1991) Prevention of insulitis and diabetes onset by treatment with complete Freund's adjuvant in NOD mice. Diabetes 40: 715-725

12. U leato D, L acy PE, K ipnis D M, K anagawa O, U nanue E R (1992) A T-cell dormant state in the autoimmune process of nonobese diabetic mice treated with complete Freund's adjuvant. Proc Natl A cad Sci 89: 3927-3931

13. $K$ atz J D, B enoist C, M athis D (1995) T helper subsets in insulindependent diabetes. Sciences 268: 1185-1188

14. Seemayer TA, Tannenbaum G S, G oldmann H, Colle E (1982) D ynamic time course studies of the spontaneously diabetic B B Wistar rat. A m J Pathol 106: 237-249

15. Logothetopoulos J, Valiquette N, M adura E, Cvet D (1984) The onset and progression of pancreatic insulitis in the overt, spontaneously diabetic young adult B B rat studied by pancreatic biopsy. Diabetes 33: 33-36

16. $\mathrm{H}$ anenberg $\mathrm{H}$, Kolb-Bachofen $\mathrm{V}, \mathrm{K}$ antwerk-Funke $\mathrm{G}, \mathrm{Kolb} H$ (1989) $M$ acrophage infiltration precedes and is a prerequisite for lymphocytic insulitis in pancreatic lesions of prediabetic B B rats. D iabetologia 32: 126-134

17. Walker R, B one A J, Cooke A, Baird JD (1988) Distinct macrophage subpopulations in pancreas of prediabetic $B$ B/E rats. D iabetes 37: 1301-1304

18. Ku L, K im MK, A mano K, Pak CY, Jaworski MA, M ehta J G, Yoon J-W (1989) Preferential infiltration of macrophages during early stages of insulitis in diabetes-prone BB rats. Diabetes 37 : 1053-1058

19. Voorbij HAM, Jeucken PHM, Kabel PJ, de Haan M, D rexhage H A (1989) D endritic cells and scavenger macrophages in pancreatic islets of prediabetic B B rats. D iabetes 38: 1623-1629

20. B one A J, Walker R, Varey A -M , Cooke A, B aird J D (1990) E ffect of cyclosporin on pancreatic events and development of diabetes in $B$ B/E dinburgh $R$ ats. D iabetes 39: 508-514

21. Ziegler A -G, E rhard J, Lampeter EF, Nagelkerken L M, Standl E (1992) Involvement of dendritic cells in early insulitis of B B rats. J A utoimmunity 5: 571-579

22. Satoh J, Shintani S, O ya K, Tanaka S-I, N obunaga T, Toyota T, Goto $Y$ (1988) Treatment with streptococcal preparation (OK432) suppresses anti-islet autoimmunity and prevents diabetes in B B rats. D iabetes 37: 1188-1194

23. Sadelain M WJ, Q in H-Y, Sumoski W, Parfrey N, Singh B, Rabinovitch A (1990) Prevention of diabetes in the B B rat by early immunotherapy using Freund's adjuvant. J A utoimmun 3: 671-680

24. K iesel U, Farine J-C, Kolb H (1994) Prevention of diabetes in B B rats by an $\mathrm{E}$. coli extract (OM-89). Int J I mmunopathol Pharmacol 7: $193-404$

25. K leemann R, R othe H, Kolb-B achofen $V$ et al. (1993) Transcription and translation of inducible nitric oxide synthase in the pancreas of prediabetic B B rats. FE BS L ett 328: 9-12

26. Suschek $C$, Fehsel $K, K$ röncke K -D, Sommer A, K olb-B achofen $V$ (1994) Primary cultures of rat islet capillary endothelial cells. A m J Pathol 145: 685-695

27. Siegling A, L ehmann M , Platzer C, E mmrich F, Volk HD (1994) A novel multispecific competitor fragment for quantitative $P C R$ analysis of cytokine gene expression in rats. J I mmunol M ethods 177: $23-28$

28. Kolb-Bachofen V, E pstein S, K iesel U, Kolb H (1988) Low-dose streptozotocin-induced diabetes in mice. D iabetes 37: 21-27

29. Kolb-Bachofen $V$, Schraermeyer $U, H$ oppe T, H anenberg $H, K$ olb $H$ (1992) Diabetes manifestation in B B rats is preceded by panpancreatic presence of activated inflammatory macrophages. Pancreas 7: 578-584

30. H uang X, H ultgren B, D ybdai N, Stewart TA (1994) I slet expression of interferon- $\alpha$ precedes diabetes in both the BB rat and streptozotocin-treated mice. I mmunity 1: 469-478

31. Löhr M , M arkholst H , D yrberg T, K löppel G, $O$ berholzer M , L ernmark $A$ (1989) Insulitis and diabetes are preceded by a decrease in $\beta$-cell volume in diabetes-prone B B rats. Pancreas 4: 95-100

32. Gepts W, LeCompte M (1985) The pathology of type I (juvenile) diabetes. In: Volk BW, A rquilla EA (eds). The diabetic pancreas. Plenum Publishing Corporation, N ew Y ork pp. 337-365

33. Somoza N, Vargas F, R oura-M ir C et al. (1994) Pancreas in recent onset insulin-dependent diabetes mellitus. Changes in $\mathrm{H} L A$, adhesion molecules and autoantigens, restricted T cell receptor $\mathrm{V} \beta$ usage, and cytokine profile. J I mmunol 153: 1360-1365

34. Jiang Z, Woda B A (1991) Cytokine gene expression in the islets of the diabetic B iobreeding/Worcester rat. J I mmunol 146: 2990-2994

35. Powrie F, Coffman RL (1993) Cytokine regulation of T-cell function: potential for therapeutic intervention. Immunol Today 14: 270-274

36. Zipris D, G reiner D L, M alkani S, Whalen B, M ordes J P, R ossini A A (1996) Cytokine gene expression in islets and thyroids of bb rats. J I mmunol 156: 1315-1321

37. Katsikis PD, Cohen SBA, Londei M, Feldmann M (1995) A re CD 4(+) T(h) 1 cells pro-inflammatory or antiinflammatory? The ratio of interleukin-10 to interferon-gamma or interleukin-2 determines their function. Int I mmunol 7: 1287-1294

38. K allmann $B, H$ üther $M$, B ertrams J, G ries $F A$, L ampeter $E F$, K olb $\mathrm{H}$ (1995) A bias towards Thl activity in the peripheral blood of recent onset type I diabetic patients. A utoimmunity 21: 52 (A bstract)

39. K allmann BA, K olb H, H üther $M$, M artin S, H ellermann M, L ampeter E F (1996) Interleukin-10 is a predominant cytokine in atopic dermatitis. A rch $D$ ermatol, in press

40. Peters D H, G oa KL (1994) O M -8980 A n initial review of its pharmacology and therapeutic potential in rheumatoid arthritis. Clin Immunother 2: 65-67

41. Polla BS, Baladi S, Fuller K, R ook G (1995) Presence of hsp65 in bacterial extracts (OM-89): a possible mediator of orally-induced tolerance? Experientia 51: 775-779 